\title{
Research on TPR in English Vocabulary Teaching in Primary Schools: A Case Study of a Primary School in Hangzhou*
}

\author{
Shan Liu \\ Hangzhou College of Commerce, Zhejiang Gongshang University, Hangzhou, China \\ Siyue Chen \\ Hangzhou College of Commerce, Zhejiang Gongshang University, Hangzhou, China
}

\begin{abstract}
As the basis of English learning, English vocabulary plays an important role in both teaching and learning. Therefore, the TPR approach proposed by James Escher is highly respected. By means of questionnaires and an interview, this paper studies the application of Total Physical Response in primary school English vocabulary teaching. It has been found that both students and teachers approve of the application of TPR in primary school English vocabulary teaching and then suggestions for children's English education have been proposed.
\end{abstract}

Index Terms - primary school, English vocabulary teaching, total physical response

\section{INTRODUCTION}

Vocabulary has long been seen as one of the key factors in language learning. It is a solid foundation in all English learning, especially in primary school English vocabulary teaching. However, for teachers, vocabulary teaching is equivalent to one of the difficulties in primary school English vocabulary teaching. So how do teachers carry out primary school English vocabulary teaching smoothly?

Most of them adopt the following teaching methods, such as intuitive teaching methods, natural spelling methods, game teaching methods, situational teaching methods, story teaching methods, etc. At the same time, TPR is a teaching method which can mobilize the enthusiasm and the initiative of learners. That is to say, learners can acquire the perception and knowledge of language through various body movements and activities, and then imitate it further so that learners can use it better. If TPR is used in primary school English vocabulary teaching, the English classroom atmosphere will be activated. TPR method can breathe new life to words. For primary school students, they like to express themselves through body movements. Therefore, the application of TPR method in English vocabulary teaching has positive educational value. When primary school English teachers teach English vocabulary, they should be good at combining textbooks to find suitable English vocabulary learning methods for students, and then can stimulate students' initiative. In this way, students can not only learn English vocabulary in a relaxed and pleasant environment, but also accumulate a large number of vocabularies while having fun, laying a concrete foundation for English learning, and ultimately cultivating students' English literacy. Ummah (2017) also thinks that it is an arduous task for teachers to teach English among teenagers, which is challenging. Teachers have to spend more time preparing to create teaching success. Only by adopting positive and effective teaching methods can teachers stimulate students' interest in learning English to the greatest extent and help students focus in the whole process of classroom learning.

Consequently, the present study mainly focuses on the following three questions:

First of all, is TPR effective in English vocabulary teaching in primary schools? Secondly, how well do students accept TPR in English vocabulary teaching?

Last but not least, how well do teachers accept the application of TPR in vocabulary teaching?

\section{LITERATURE REVIEW}

TPR is the abbreviation of the Total Physical Response teaching method, which was put forward in the 1960s by James Asher, a celebrated American psychology professor. TPR is a comprehensive teaching method, which combines

\footnotetext{
${ }^{*}$ This paper has been sponsored by the Research Project of Zhejiang Association of Foreign Languages\& Literatures: Construction and Research of New Paradigm of Foreign Language Mixed Teaching in Universities with the Background of "New Business" from the Perspective of Artificial Intelligence (No. ZWYB2019023), Zhejiang Gongshang University Higher Education Research Project: Construction and Research of New Paradigm of Foreign Language Mixed Teaching in Universities with the Background of "Big Business" from the Perspective of Artificial Intelligence: A Case Study of Fanya Platform (No. xgy1952), and the 13th Five-Year Plan Teaching Reform Project of Zhejiang Province: A Study of College English Teaching Reform Aiming at the Cultivation of New Business Talents from an International Perspective (No. jg20180483).
} 
language learning with body movements. Learners can use their body movements to help them memorize the target language better. The key teaching activity of TPR is not only to issue commands, but also to respond to commands. That is to say, on the basis of students' understanding of the command and making correct and corresponding responses to the command, students can also imitate the teacher, and then issue the command to other students, and other students will also respond to the student's command. In short, teachers guide students with words and students respond with actions in TPR class.

\section{A. Previous Studies on TPR in China}

Generally speaking, the research of TPR in English teaching started relatively early in foreign countries. However, with the implementation of China's basic education reform and quality education, TPR method has also aroused wide concern by many other scholars in China. At the end of the 20th century, China introduced the TPR method, and then a great number of domestic scholars also tried to apply it to English teaching. Scholars at first maintained a conservative attitude. For instance, Xie (1997) thinks that TPR teaching method is only applicable to children's language learning. To some extent, it is easier for children to learn foreign languages than adults because they have better memory than adults, and the psychological burden of children is lighter than that of adults. To conclude, the ability and effect of children to master a second language is better than that of adults.

Since the beginning of the 21 st century, TPR method has gradually been widely welcomed, especially in primary and secondary school English Teaching in China. More and more scholars believe that this new method of learning a foreign language can be popularized in China. Hu (2000) discussed the differences between the traditional English teaching method and TPR teaching method in China, as well as the advantages of TPR method. He believes that TPR teaching method is a teaching process, which follows the internalization of operations. When teachers use TPR in teaching, they don't have to pay too much attention to correcting students' grammatical errors, which can stimulate students' enthusiasm in language learning. Wang (2004) believes that TPR method can make students learn English with pleasure in the real experience. TPR mode can not only fully mobilize students' senses, but also fully arouse students' interest in learning, and even make English learning full of vitality, so as to hold on to students' English interest in learning. Similarly, Wang (2005) holds that TPR teaching method can create a relaxed and pleasant learning environment, so as to reduce the psychological burden of students. So that they can learn English in a state of zero learning pressure. Another special feature of TPR teaching method is that teachers can use body language, which cuts down the communication distance between teachers and students. It could also increase the affection between teachers and students.

$\mathrm{Wu}$ (2013) reported an empirical study on the application of TPR in English teaching for children that was based on a kindergarten and took nearly three months. The results show that TPR English teaching is not only more attractive to children in the teaching process, but also enhances students' listening comprehension ability. What's more, it can also help students keep a relatively high retention rate of what they have learned.

\section{B. Previous Studies on TPR Aboard}

TPR has a long history of English teaching abroad, and its research started earlier. Since 1969, James Asher, the founder of TPR teaching method research, has designed and implemented a series of experiments. In one study, Asher (1969) compared the comprehension and memorization of Japanese among college students who had not studied Japanese and found that the experimental group with TPR teaching performed significantly better than the control group. Later, Asher conducted the same experiment on Russian students, and the results were actually the same. Therefore, Asher believes that TPR teaching method emphasizes the combination of body movement and language learning. TPR focuses on interactive behavior in the process of second language learning. The outstanding feature of TPR is that it allows students to learn in a relaxed and pleasant environment, which makes students develop greater interest in language learning, and it is easier to accept the target language.

In addition to Asher, there are many other scholars who have done much research on language acquisition, which shows that TPR is beneficial to language acquisition. Wolfe and Jones (1982) conducted a 13-week experiment in a Spanish class at middle school level 1 and found that the TPR method creates an easier learning environment for learners

Ellis (1994) proposed that TPR is necessary for language beginners. He believes that it is the most perfect for beginners and that it is a good form of classroom activities for students to respond to teachers' instructions with body movements.

Through experiments, it has been proved that when adults are put into the language environment of body movements, they can achieve the same learning effect as children. In the experiment, Asher (2009) took students who had not studied Japanese as subjects. In the test, the experimental group made action response to instructions, while the control group only watched the performance, but did not make action response. Experiments show that the experimental group excelled than the control group in both long sentence learning and short sentence learning. Later, he found in the experiment that adolescence is a critical period for learning foreign language pronunciation. If students are sent to live in the target language country before puberty, they are likely to learn fluent pronunciation. If they are after puberty, it will be more difficult. 


\section{Deficiency of Previous Studies on TPR}

Based with the research of domestic and foreign scholars, it could be said that TPR teaching method has many advantages in English teaching, while in other aspects, especially in the aspects of English learning, there is little research. Foreign research on TPR teaching method relies on the empirical validity of this method, but rarely involves the research on TPR teaching method in primary school foreign language teaching. However, although Chinese scholars hold different opinions on the research of TPR teaching method, they only focus on English learning as a whole.

For example, the research on vocabulary and sentence pattern, and the experimental research on specific parts of English teaching has rarely been conducted.

\section{Present Situation of Studies on English Vocabulary Teaching in Primary Schools}

Primary school stage can be said to be the prime time for children to learn, and English vocabulary is a basic part of primary school English. So mastering and using a certain amount of vocabulary is one of the significant tasks for primary school students. Therefore, vocabulary teaching plays an important role in primary school English teaching, which has been the focus of extensive research.

Yin (2013) believes that English vocabulary is like the cornerstone of a building, and it is also a key to opening the door to English. If the pupils master the words well, it will help them to understand authentic English correctly. Learning vocabulary can also help pupils to build up their confidence in learning English. Hu (2018) analyzed the situation of English Vocabulary Teaching in primary schools, and came up with some useful methods to develop English vocabulary learning ability so as help students in primary schools.

Since the new curriculum reform, English Teaching in primary schools in China has gradually shifted from exam-oriented education to quality education. Nevertheless, there are still many problems to be solved in primary school English vocabulary teaching. First of all, from the current point of view, the teaching methods of primary school English vocabulary learning are relatively limited in number. Either the teacher leads the reading, and then students follow; or the teacher finds a student to lead the reading and other students follow suit like a machine. In short, they read it repeatedly. Secondly, there is a lack of connection between words, and the teaching process lacks the consolidation of words. Hence, this kind of learning makes students unable to develop deep memorization of the English vocabulary they have learned. Thirdly, the introduction of vocabulary learning methods and strategies is critically needed. In the past, the teaching mode mainly relied on teachers to impart knowledge to students, which ignored the importance of learning methods. In this way, it is impossible to cultivate students' self-taught ability. Finally, vocabulary teaching in primary schools generally ignores regular review. If learners don't review English vocabulary after learning, they are likely to forget all the words learned.

\section{MethodOLOGY}

This part illustrates the methodology, involving subjects and research methods.

\section{A. Subjects}

A primary school in Hangzhou, Zhejiang Province was chosen. This primary school has good teaching equipment and qualified teachers who know some teaching methods including TPR. Therefore, a questionnaire survey and interviews with teachers could be conducted. There are 20 teachers in the questionnaire survey. They are teaching more than one grade, that is to say, teachers may teach students across grades. These teachers mainly teach students in Grades 3-6. For purpose of finding out how well students accept the application of TPR in primary school English vocabulary teaching, Grade-Three students were chosen by the researcher. They were from Class Two and Class Three respectively.

There were 40 students in each of the two classes. A total of 80 students participated in the survey, including 33 boys and 47 girls in total. The results are shown in Table 3-1. Most of them just began to learn English. This means that they are just beginners of English learning. Therefore, they always encounter some problems in learning a second language besides their mother tongue.

TABLE 3-1

GENDER OF SUBJECTS

\begin{tabular}{|c|c|c|}
\hline Gender & Amount & \multicolumn{2}{|c|}{ Percentage } \\
\hline Boys & 33 & $41.25 \%$ \\
\hline Girls & 47 & $58.75 \%$ \\
\hline
\end{tabular}

\section{B. Research Methods}

The questionnaire survey and the interview are used to complete the data collection process. Before the questionnaire survey, it has been learned that TPR has been used in English vocabulary teaching in this primary school. The questionnaire survey was used twice by the author, one for teachers and the other for students. The questions from the two questionnaires are put forward from the perspective of teachers and students respectively. These problems are of great significance to the research of this paper. 


\section{Questionnaire Survey}

The questionnaire survey is used to collect students' views on vocabulary learning. As the subjects are the third-grade students, the researcher asked the teacher to explain each question to the students in detail, so that they can understand the meaning of each question in the questionnaire and increase the reliability of the questionnaire. This prevents unreliable results. The teacher explained that the questionnaire has nothing to do with the final score of the students and the students could completed the questionnaire according to their actual situation.

In the first questionnaire, there were 17 questions. 80 copies were distributed, and 80 were withdrawn. The form of the questionnaire was multiple choices. The questionnaire includes the following dimensions: Students' interest in English vocabulary learning (questions 1-2), students' cognition of vocabulary learning (questions 3-6), students' participation in class (questions 7-10), the atmosphere of vocabulary learning (questions 11-12), the effectiveness of vocabulary learning (questions 13-15), and the attention of vocabulary learning (questions 16-17). Therefore, the questionnaire is based on the situation of the subjects. The questionnaire attempts to find out the effectiveness of using TPR in vocabulary teaching, so as to get the forward-looking ideal which is conducive to the formulation of education policy.

The second questionnaire, with a total of 10 questions, is for teachers. The contents of the questionnaire include the following dimensions: the basic situation of teachers' vocabulary teaching (1-2), teachers' application of TPR (3-7), teachers' views on TPR (8-10), and Item No. 11 are about whether teachers have participated in training. The subjects of this survey are English teachers in this primary school. The 20 copies of the questionnaire have been distributed and withdrawn, and all of them are valid.

\section{Interview}

In order to further understand the teachers' views on the use of TPR in teaching, three teachers were interviewed. Before the interview, the researcher explained the purpose and intention of the interview to the respondents, and the teachers were encouraged to express their true views on TPR method, and then the researcher recorded what they said immediately. The question about teachers' acceptance of TPR involves three aspects: 1. Do you think it is necessary to use TPR in English vocabulary teaching? 2. What do you think are the advantages and disadvantages of TPR compared with other teaching methods? 3. If you were to reform TPR, what valuable suggestions would you like to put forward?

\section{RESUlTS AND ANALYSIS}

The analysis is based on the data of questionnaires collected from 80 students and 20 English teachers from a primary school mentioned above, by means of the WeChat small program "Survey Star" and the use of Microsoft Excel data analysis.

\section{A. Analysis of the Effectiveness of TPR in Vocabulary Teaching}

Aiming at answering this question of the effectiveness of TPR in vocabulary teaching, the researcher conducted a questionnaire survey on the third-grade students of a primary school in Hangzhou, and made a detailed statistical analysis. The purpose is to verify the effectiveness of TPR in vocabulary teaching.

TABLE 4-1

SUBJECTS' INTEREST IN ENGLISH VOCABULARY LEARNING

\begin{tabular}{|c|c|c|}
\hline & Amount & Percentage \\
\hline Interested in & 69 & $86.26 \%$ \\
\hline Not sure & 8 & $10 \%$ \\
\hline Not interested in & 3 & $3.75 \%$ \\
\hline
\end{tabular}

In the first question of the questionnaire, the students were asked to answer whether they were interested in English vocabulary learning. Among the 80 students, $86.26 \%$ said they were interested in English vocabulary learning, as shown in Table 4-1.

TABLE 4-2

INFORMATION ABOUT THE EFFECTIVENESS OF LEARNING VOCABULARY

\begin{tabular}{|c|c|c|c|}
\hline Number of people & A (Being effective) & B (Not sure) & C(Being ineffective) \\
\hline 13 & 75 & 5 & 0 \\
\hline 14 & 64 & 13 & 3 \\
\hline 15 & 64 & 15 & 1 \\
\hline
\end{tabular}




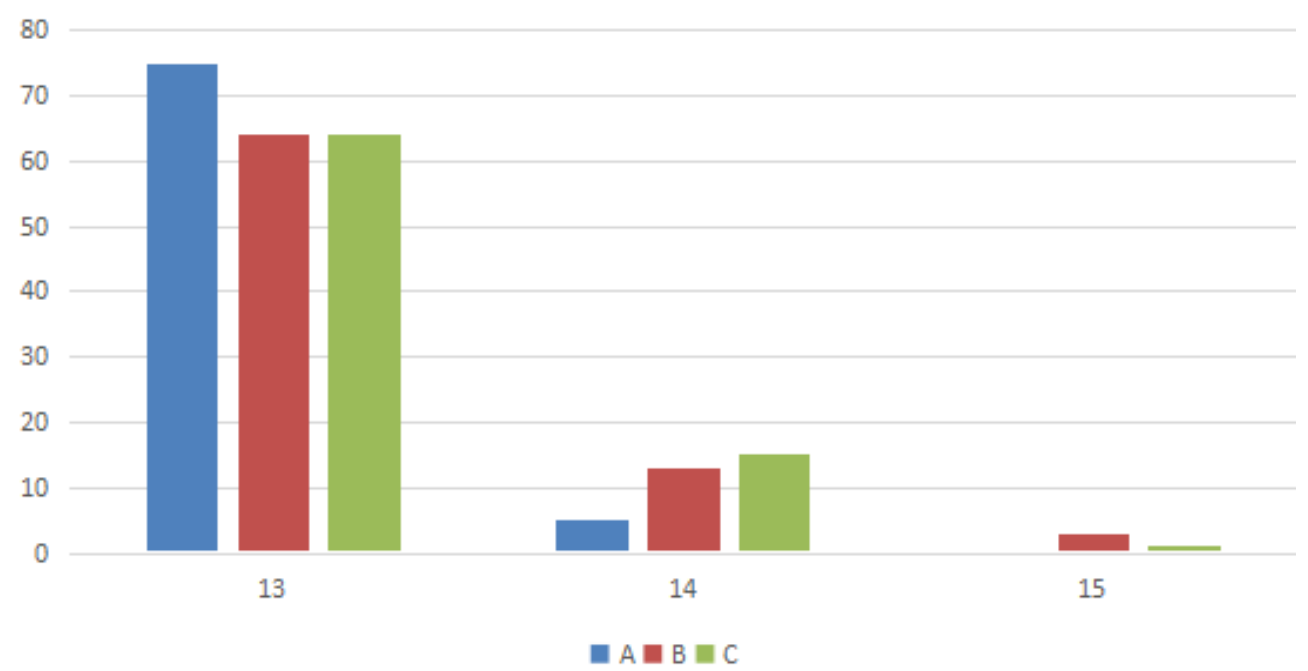

Figure 4-1 Information on the effectiveness of vocabulary learning

According to Question 13, 93.75\% of the students think that the teacher's praise can make the learning more positive. If the teacher praises the students properly when the teacher teaches students the words, this method can improve the students' learning efficiency and make the learning of words more efficient. Only $6.25 \%$ of the students hold the opposite opinion.

The result of Question 14 shows that $80 \%$ of the students believe that following the teacher's action to learn words can help improve their English learning, and $16.25 \%$ of the students are not clear. $3.75 \%$ of the students answered "No". It can be seen from the statistical results of Question 15 that $80 \%$ of the students think that when the teacher uses games, actions, pictures and other auxiliary teaching devices, their vocabulary learning efficiency is very high, that is, they can remember new words faster, and the students' learning will become easier. TPR teaching method is a lively and vivid teaching method closely related to action. It is necessary to use it in class for a long time to improve students' English learning. From the data of the results of questions 13, 14 and 15, it could be found that the application of TPR in vocabulary teaching is effective. Therefore, it is necessary to use this new vocabulary teaching method to improve students' interest and motivation in English learning.

TABLE 4-3

STUDENTS' ATTENTION IN LEARNING WORDS IN ENGLISH CLASS

\begin{tabular}{|c|c|c|}
\hline & Amount & Percentage \\
\hline Able to concentrate and listen to the class carefully & 50 & $62.5 \%$ \\
\hline Sometimes attentive, sometimes absent-minded & 28 & $35 \%$ \\
\hline Daze or absent-minded & 2 & $2.5 \%$ \\
\hline
\end{tabular}



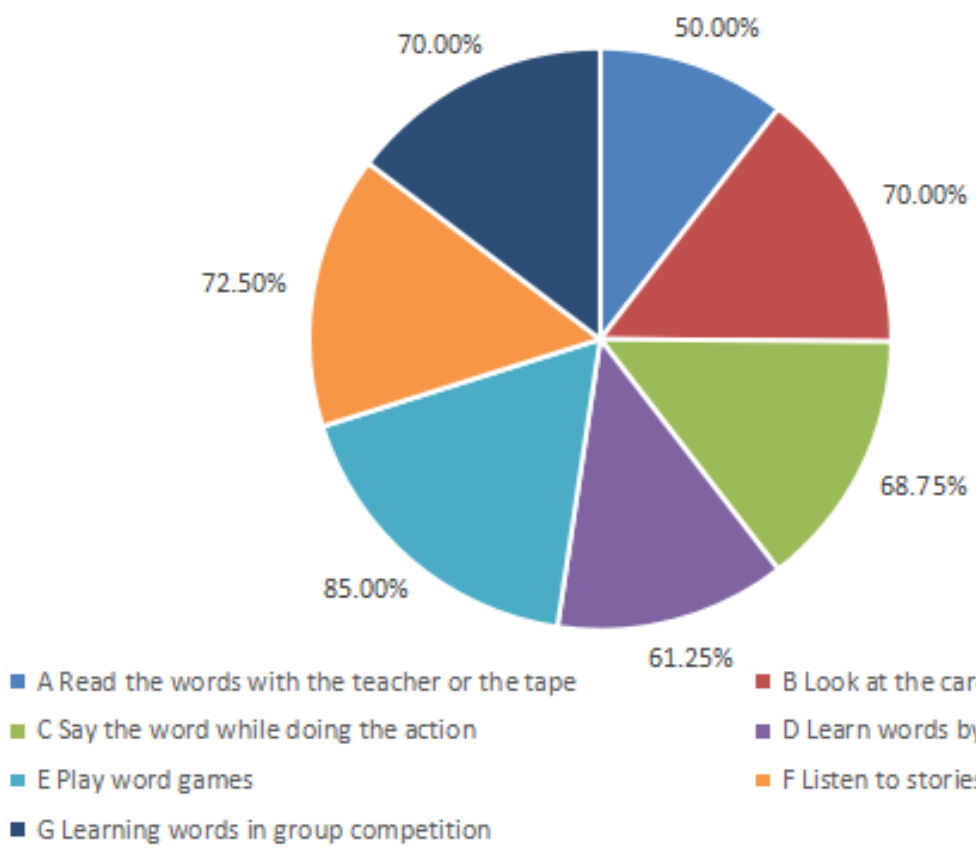

Figure 4-2 Ways to attract students' attention in learning English words

From Table 4-3, it can be seen that most students can concentrate their attention in the classroom when using TPR, so TPR can catch the students' attention. The conclusion drawn from Figure 4-2 is that students prefer these ways of learning vocabulary, and word games account for $85 \%$ of the total. Relatively speaking, the proportion of students who choose to follow the teacher or record the words is not high, only $50 \%$. Therefore, it could be concluded that TPR teaching method is in line with children's psychology and thus effective in primary school English vocabulary learning.

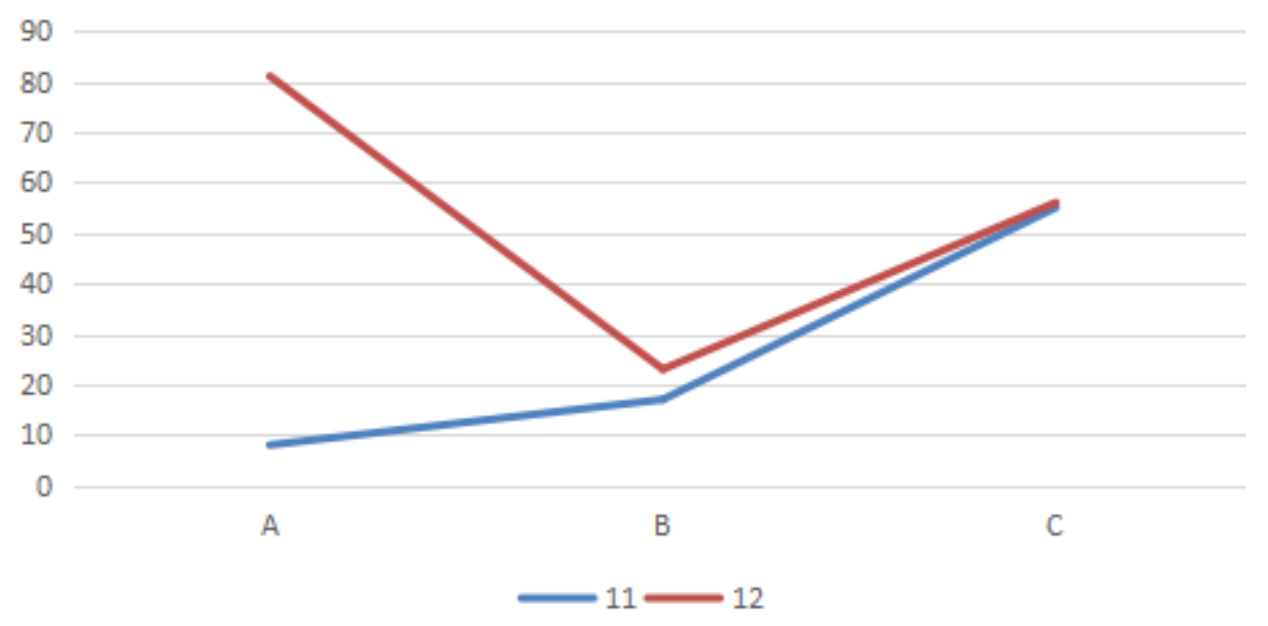

Figure 4-3 Learning atmosphere

Additionally, from the analysis of the results of the questionnaire 11 and 12 based on Figure 4-3, we can draw the following conclusion: students like a relaxed and pleasant learning atmosphere. When the teacher applies TPR to primary school English vocabulary teaching, students feel that the classroom atmosphere is not tense, which is conducive to better vocabulary learning. In TPR English class, there is a non-pressure environment, so students will be more confident in vocabulary learning.

Through the above analysis, it can be concluded that TPR is effective when it is applied to English vocabulary teaching.

\section{B. Analysis of Students' Acceptance of TPR Teaching}

Question 3 is mainly used to investigate how the teacher teaches English words in class. The results show that $75 \%$ of the students choose to play games, and $51.25 \%$ of the students choose password action. These two ways are in line with the second language acquisition theory and memory trace theory, so they are conducive to students' English vocabulary learning. 


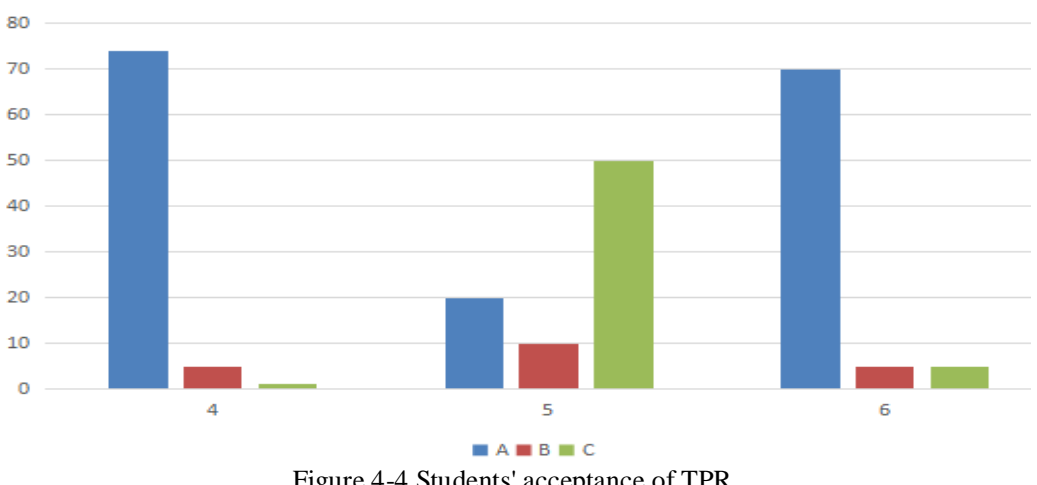

Figure 4-4 Students' acceptance of TPR

According to the data of Question 4, none of the 80 students dislike TPR teaching method and 75 students like TPR teaching method. From the perspective of students, they accept TPR teaching method, and TPR is also a teaching method in line with students' psychological needs. Question 5 discusses the traditional way of learning words. As shown in the data in Figure 4-4, 62.50\% of the students don't like the way the teacher teaches the words before. It's just a way in which students are forced to follow the teacher to read vocabulary over and over again. This kind of mechanical memory will make students feel tired and lose interest in learning. For Question 6, which is about whether students can easily remember the words through the teacher's physical activities and games, $87.50 \%$ said yes, which fully shows that students favor the TPR teaching method. TPR is a teaching method closely related to language and action, which can win the heart of students.

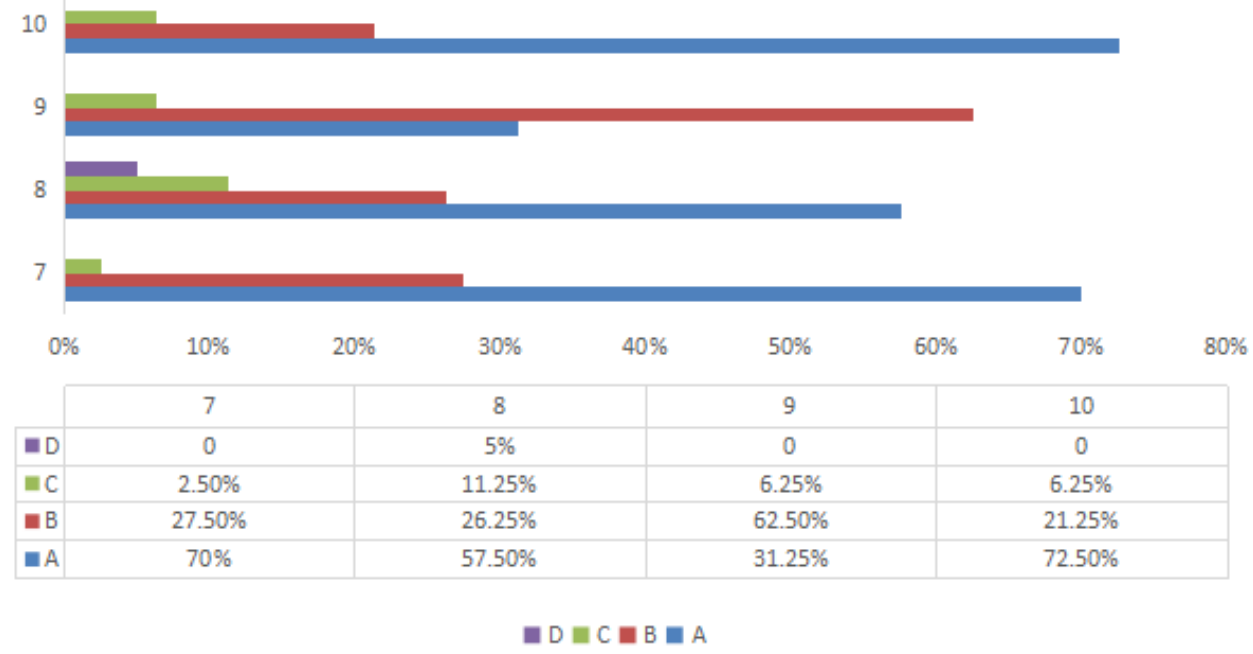

Figure 4-5 Students' participation in class

From Questions 7 to 10 of Questionnaire 1, we can see that teachers often invite students to answer questions when using TPR in vocabulary teaching, and students are very willing to take the initiative to answer the teacher's questions, which can also make students pay more attention, and students can even actively participate in the classroom. At the same time, it also confirms the relevant theory of TPR, that is, by listening first, then speaking, and then doing actions. In this way, students deepen their understanding of the language and improve their vocabulary learning. According to Question 9, only 6.25\% of the students dare not answer the teacher's questions because they are afraid of being criticized for wrong answers. Most of them are shy and dare not raise their hands. However, from Question 10, it has been found that $72.50 \%$ of the students would actively participate in the classroom when the teacher used games, group games, action to teach words. From the choice of these questions, we can see that students prefer the TPR teaching method for students could become the masters of the classroom under TPR. Moreover, students' comprehension ability can be improved through action learning. In addition, their enthusiasm in learning English could also be enhanced.

\section{Analysis of Teachers' Acceptance of TPR in English Vocabulary Teaching}

Questionnaire 2 was distributed to all English teachers in this primary school in Hangzhou with the purpose of exploring the teachers' acceptance of the application of TPR in primary school English vocabulary teaching. The results are as follows: 


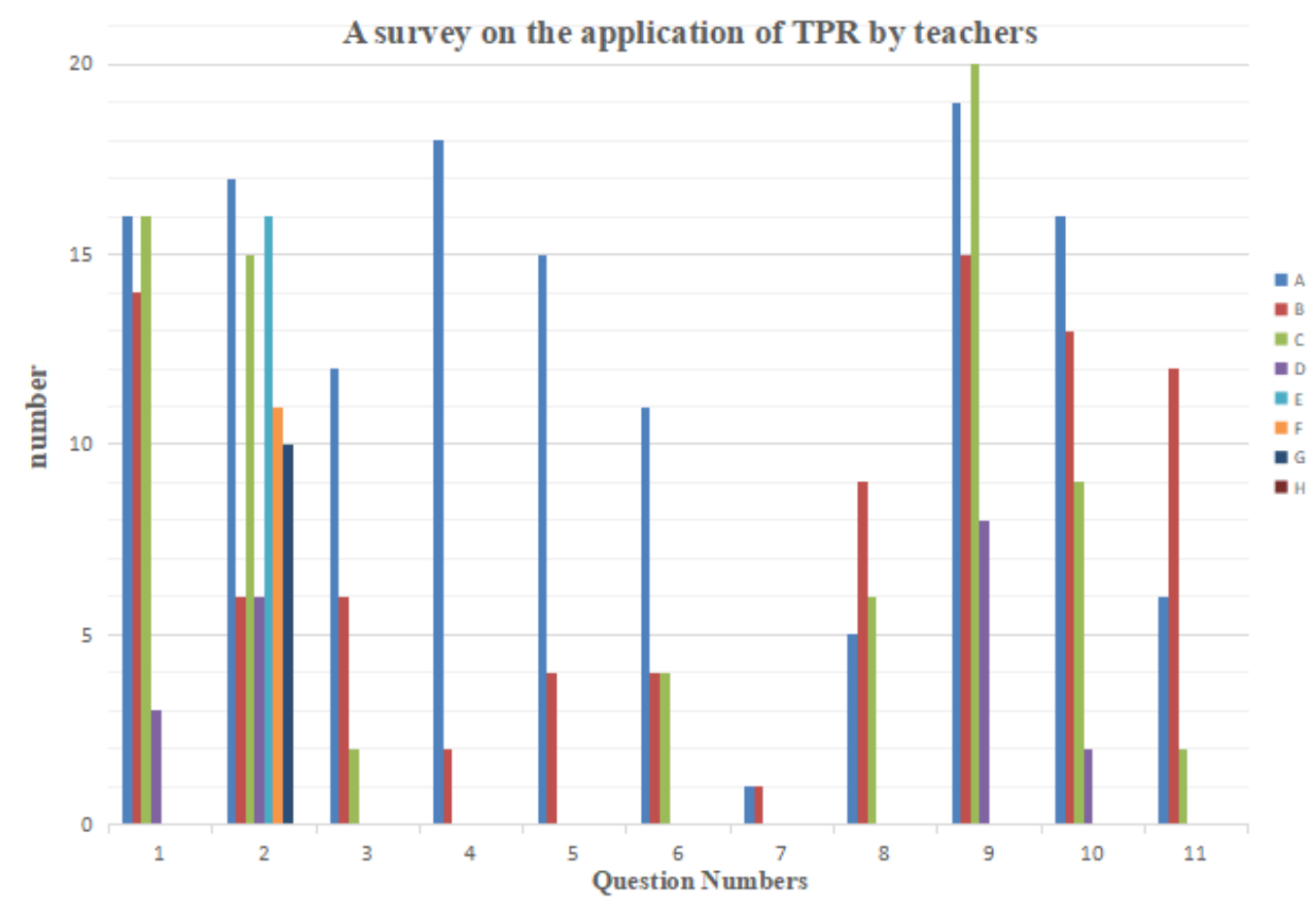

Figure 4-6 A survey on the application of TPR by teachers

From the survey results, it could be found that most of the teachers will use games, pictures, role-playing teaching strategies to teach vocabulary. The data of Question 3 shows that $60 \%$ of teachers often use TPR teaching methods. It seems that TPR is a teaching method approved of by teachers as well. For Question 4, 95\% of the teachers said that when teaching new verbs, they would first demonstrate the verbs to the students through their own body language. From this, we can infer that teachers are willing to teach students words in this way. Only two teachers do not use TPR. The reason why they choose not to do so is reflected in Question 7. One teacher thinks the class time is limited and can't organize everyone to participate in it. The other teacher thinks that students prefer to sit and watch the teacher's performance or watch the slide show. And for Question 5, teachers who use TPR method agree with this way of teaching words. They believe the effect of the TPR method is very beneficial, which is conducive to students' learning. As to question 6, teachers all answer that students like this kind of teaching method. When answering Question 8, teachers tend to hold the TPR teaching method is a waste of time to some extent. For Question 10, teachers gave their own opinions on the difficulties of TPR. $80 \%$ of the teachers hold that with the large number of students, the whole class is not easy to control, and $65 \%$ of the teachers think that it is the limitation of the teaching environment. Many activities cannot be carried out easily. The advantages of TPR are as shown in Question 9. All teachers choose TPR to capture students' attention, and $95 \%$ of the teachers also choose TPR to activate the classroom atmosphere. For Question 11, 60\% of the teachers did not participate in any TPR training, but they have learned about it through other channels. It is proved that TPR teaching method is accepted by teachers from the choice of these four questions, which is effective.

As one of the research tools, interview is used to answer the third question. It is a supplement to the questionnaire and aims to get more information about teachers' views on the application of vocabulary in primary school English teaching. All the teachers surveyed agree that it is necessary to use TPR in English vocabulary teaching in primary schools, and they support that TPR is beneficial to English vocabulary learning and students will have more confidence in learning English in the future. Through the TPR teaching method, the relationship between teachers and students could be more harmonious. From the answers of the three teachers interviewed to the three questions, it could also be concluded that teachers support TPR in the English vocabulary teaching class.

\section{CONCLUSIONS}

Through the questionnaire survey, it has been found that the primary school students are interested in English vocabulary learning. They like to participate in group games and are willing to accept this way. In the questionnaire survey and the interview with the teachers, it has been found that the implementation of the TPR teaching method not only mobilize the students' senses, exercising their body, but also make their thinking more sensitive. Teachers use games, actions and other forms to provide students with a pressure-free learning environment, so students can learn English in a happy way. Therefore, we can conclude that TPR is a more effective method of vocabulary teaching than traditional vocabulary teaching methods. Through questionnaires and interviews, it could be concluded that the TPR teaching method not only facilitates teachers' teaching work, but also promotes the harmonious relationship between 
teachers and student. The TPR teaching method is also consistent with the concept of cultivating students' comprehensive quality proposed in the current English education reform in China, which provides a theoretical basis and direction for the reform of English education and teaching in China.

In the process of investigation, several problems have been spotted. Although TPR teaching method plays an important role in primary school English vocabulary teaching, it cannot be ignored that children with different personalities will have different results in vocabulary learning efficiency. In other words, introverted children are less willing to participate in the course. In addition, the body movement of vocabulary teaching in each class should not be too much, too many words will contribute to students' memory confusion, and even cause classroom fatigue, because it consumes too much physical strength of students.

Consequently, suggestions have been put forward: When using TPR teaching, teachers should encourage shy students and give them more opportunities to perform in class; teachers should employ teaching methods that are close to students' life and in line with their age; finally, schools should give primary school English teachers more opportunities of professional training.

To conclude, it has been found that TPR are welcomed by students and teachers alike. More studies are expected to be conducted on the application of Total Physical Response in primary school English vocabulary teaching so as to improve the efficacy of English teaching in primary schools.

\section{REFERENCES}

[1] Asher, J. (1969). The total physical response approach to second language learning. The Modern Language Journal, 1, 3-17.

[2] Asher, J. (2009). Learning Another Language Through Actions. California: Sky Oaks Productions, Inc.

[3] Ellis, R. (1994). The Study of Second Language Acquisition. Shanghai: Shanghai Foreign Languages Education Press.

[4] Hu, Lifeng. (2018). Research on Primary School Vocabulary Teaching. Reform Research, 1, 22-22.

[5] Hu, Tieqiu. (2000). TRP---A New Approach in Foreign Language Teaching. Chinese Science \&Technology Translators Journal, 1, 34-43.

[6] Ummah, S. (2017). The Implementation of TPR (Total Physical Response). Method in Teaching English for Early Childhood, 58, 421-428.

[7] Wang, Yiming. (2004). Application of TPR to Primary School English Teaching. Journal of Basic English Education, 6, 48-49.

[8] Wang, Chunfen. (2005). Application of TPR to Junior High School English Teaching. Journal of Normal College of Liupanshui, $17,70-72$.

[9] Wolfe, D. E. \& G Jones. (1982). Integrating Total Physical Response Strategy in a Level I Spanish Class. Foreign language annals, 15, 273-280.

[10] Wu, Fei. (2013). A Study of the Application of TPR Approach in Teaching Preschool Children English. Jinan: Shandong Normal University.

[11] Xie, Jingyuan. (1997). A Brief Analysis of the Application of TPR in China. Journal of Heilongjiang College of Education, 2 , 83-83.

[12] Yin, Jia. (2013). On the Importance of Vocabulary in Primary School English Learning. Communication Methods, 5, $112-113$.

Shan Liu was born in Kaifeng, China in 1983. She received her master's degree in foreign linguistics and applied linguistics from Zhejiang University, China in 2008. She is currently a lecturer in Hangzhou College of Commerce, Zhejiang Gongshang University, Hangzhou, China. Her research interests include second language acquisition, foreign language teaching and research, translation research and pragmatics.

Siyue Chen was born in Hangzhou, Zhejiang. She is currently a student in Hangzhou College of Commerce, Zhejiang Gongshang University. Her research interests include second language acquisition and foreign language teaching. 